\title{
RETARDED EMBRYONIC DEVELOPMENT AND PREGNANCY TERMINATION IN OVARIECTOMIZED GUINEA-PIGS: PROGESTERONE DEFICIENCY AND DECIDUAL COLLAPSE
}

\author{
RUTH DEANESLY \\ A.R.C. Institute of Animal Physiology, \\ Babraham, Cambridge \\ (Received 5th February 1971, accepted 29th Fuly 1971)
}

Summary. Progesterone deficiency in the pregnant guinea-pig, ovariectomized before implantation, retards growth of the conceptuses and embryos and terminates pregnancy on or before Day 16.

In a fresh investigation, conceptuses from ovariectomized, 12- to 16day pregnant females were examined in serial sections, and from Day 12 a conspicuous degeneration of part of the decidua occurred, interfering with the normal development of the adjacent placenta. This degeneration undoubtedly contributed to the retardation of the conceptus during the following days, when very active embryonic differentiation was normally taking place. It was the total collapse of the decidua with massive haemorrhage, almost always on Day 16, which abolished surviving pregnancies. Similarly in the unmated guinea-pig, the traumatic deciduoma breaks down at the end of the 16-day cycle, when the corpora lutea regress before the next oestrus.

Decidual degeneration could be prevented in ovariectomized females if progesterone was given sufficiently early in pregnancy. In other developing conceptuses, however, in which progesterone had been deferred till later, an area of decidual degeneration, no longer in contact with the placenta, could persist for some days.

The rôle of the decidua in early pregnancy is discussed.

\section{INTRODUGTION}

It has been shown previously that ovo-implantation, in the guinea-pig on Day 6 or 7 of pregnancy, was not prevented by ovariectomy 3 to 5 days after mating. Embryos at first developed normally but without exogenous progesterone became retarded, and generally died by Day 16 (Deanesly, 1963). In spite of this, some would grow and survive if progesterone was given to the mother from Day 15 or earlier. Normal embryos show rapid growth and differentiation during the 14- to 16-day period (Harman \& Prickett, 1932; Scott, 1936).

It was decided that a fresh histological study of the effects of ovariectomy might throw light on the essential rôle of progesterone in early pregnancy and 
explain the variable growth and survival of the conceptuses and in particular the sudden termination of pregnancy on Day 16. In serial sections the earliest and the cumulative effects of progesterone could be distinguished.

\section{MATERIAL AND TEGHNIQUE}

Guinea-pigs and operative technique were as previously described (Deanesly, 1963, 1967). The morning of the vaginal plug was Day 0, and ovariectomy was done before ovo-implantation, usually on Day 4 or 5 of pregnancy. Conceptuses were examined from eleven normal 13- to 18-day pregnant guineapigs (three of them parous), and from twenty ovariectomized, pregnant guinea-pigs (seven of them parous); four of the ovariectomized females received progesterone and another received a synthetic progestagen, norgestrel (Edgren, Jones, Clancy \& Nagra, 1968).

Colcemid (Ciba), $1 \mathrm{mg} / \mathrm{kg}$ body weight, was administered intraperitoneally to normal and ovariectomized females $1 \frac{1}{2}$ to $2 \mathrm{hr}$ before death to facilitate a comparison of cell divisions in the developing conceptuses. At autopsy, conceptuses were measured and weighed, unless, from their shape and appearance, they were obviously regressing. Usually the largest and best shaped conceptuses were preserved for histology.

Fixation was in Bouin's or Susa's fluid, and material was reweighed after transfer to $70 \%$ alcohol. Serial sagittal sections were made through the conceptuses after vacuum imbedding; according to requirements, one in ten, one in six or every section was mounted. Staining was in haematoxylin and eosin.

Progesterone (and similarly norgestrel), was given as solid, weighed tablets, placed under the skin; at autopsy, they were dried and reweighed for an estimate of average daily absorption. The five females in this group were included to illustrate the effects of progestagen on the histological and other changes in conceptuses arising after ovariectomy of the mother.

\section{EXPERIMENTAL RESULTS}

Comparison of conceptuses in normal and ovariectomized guinea-pigs

The early development of the normal embryo of the guinea-pig has been described by Harman \& Prickett (1932) and Scott (1936). Heart, somites and allantois develop from Day 14 and differentiation is rapid during Days 14 to 16.

At the 13-day stage, conceptuses were examined from one normal and three ovariectomized females; two of these had only one conceptus, which was well shaped but small. In section (Pl. 1, Fig. 3), a conspicuous degeneration of the mesometrial part of the decidua, immediately in contact with the developing placenta, could be seen surrounded by haemorrhage, as in Pl. 3, Fig. 12. In normal 13- to 15-day conceptuses, the decidual cells are more loosely arranged here than in other regions nearer to the uterine wall. This early result of progesterone deficiency seems to have affected the growth of the placenta, which is thinner than in the corresponding normal conceptus. It was later found that similar decidual breakdown had already occurred in a 12-day conceptus from an ovariectomized female. In spite of this decidual degenera- 
tion, it was known that conceptuses were still viable if progesterone was given from Day 13 (Deanesly, 1963). Cell division was continuing in embryos, placentae and outer regions of the decidua.

At 14 days, conceptuses from normal and ovariectomized females varied considerably, but those from normal females were distinctly larger and more differentiated than at 13 days. The placenta had thickened and become more compact and the subplacenta had begun to form. There was no decidual regression (Pl. 1, Fig. 1).

Conceptuses from two of the three ovariectomized guinea-pigs were much smaller than normal ones and the embryos were retarded; the decidua had again broken down with haemorrhage adjacent to the placenta which was very poorly developed (PI. 3, Fig. 12). In the third ovariectomized guinea-pig, which was parous, one of the three conceptuses appeared normal at autopsy both in size and shape (Pl. 1, Fig. 4), but the placenta again was thin and extended and the decidua at an early stage of breakdown, in which the dead cells had not yet been resorbed. There was the usual haemorrhage. The embryo had developed normally and cell division could be seen. The other two conceptuses in this parous female were regressing. As in previous experiments, less than half of the embryos in ovariectomized mothers survived to Day 14.

Two normal conceptuses were sectioned at 15 days and five from three ovariectomized mothers. Normal conceptuses and embryos had grown actively in the previous $24 \mathrm{hr}$ and now had large hearts and up to thirteen somites. Plate 1, Fig. 2 shows an enlarged conceptus, concentration of the placenta and a differentiating embryo. Other sections included the developing subplacenta and small allantois. There appeared to be some erosion of decidual tissue in contact with the subplacenta but cells had not disappeared over a distinct area as after maternal ovariectomy. The conceptuses from ovariectomized females varied in size and condition at 15 days. One, from a parous female, was only half normal size, but there was no conspicuous decidual degeneration; embryo and allantois had differentiated, as had the subplacenta where there was active cell division. However, the blood sinuses were very congested and total regression of the conceptus appeared imminent.

Contrasting with this small 15-day conceptus were those in a female mated post partum which was ovariectomized on Day 6 . This animal had eight conceptuses which appeared normal in size (about $1 \mathrm{~g}$ ) and shape at autopsy. Sections through a twin implantation site (Pl. 1, Fig. 5) showed well differentiated embryos, but much decidual degeneration, which was spreading round from the mesometrial region to the anti-mesometrial region. The placenta was thin and extended. A single conceptus from the same female was basically similar, except that the subplacenta had begun to form. The area of decidual breakdown was extending. It is possible that in this female the later ovariectomy and the number of corpora lutea had somewhat delayed the onset of progesterone deficiency and permitted greater growth of the conceptuses, without affecting the general course of events.

In the third 15-day parous ovariectomized female, all three conceptuses were clearly regressing and had lost shape. Sections through one of them showed 


\section{EXPLANATION OF PLATES 1 TO 3}

Abbreviations: all., allantois; dec., decidua; deg., degenerating; emb., embryo; haem., haemorrhage; plac., placenta; y.s., yolk sac.

\section{PLATE 1}

Sagittal sections through 13-, 14- and 15-day conceptuses, the embryos lying towards the base of the sections except in Pl. 1, Fig. 4. $\times 4.9$.

FIG. 1. No. 34. Normal 14-day conceptus. Placental tissue has become concentrated mesometrially and projects into the decidua. The embryo shows organ differentiation.

Frg. 2. No. 28. Normal 15-day conceptus; other sections show the developing subplacenta and a large allantois. The embryo has seven to eight somites.

Fig. 3. No. 24. A 13-day conceptus from an ovariectomized female. Already there is marked degeneration of decidual tissue over large areas. The embryo, however, appears healthy, with the head folds just coalescing.

Fic. 4. No. 23. A 14-day conceptus from a parous ovariectomized female. This conceptus, including the embryo, is much better developed than that of Fig. 3 and illustrates the variation in the series. By comparison with the normal conceptus (Fig. 1), placental tissue is scanty and the decidua is beginning to break down; the dark areas in the decidua consist of apparently phagocytic fibroblasts.

Fig. 5. No. 12. Twin 15-day conceptuses from a parous ovariectomized female showing early decidual regression and poor development of embryo and placenta, the latter thin and extended.

Fic. 6. No. 50. A 16-day conceptus, below normal in size and development, but well shaped, from an ovariectomized female which received an average of $1.5 \mathrm{mg}$ progesterone daily from Day 12 to Day 15. The decidua has been maintained and the embryo, though small, is developing normally. The allantois is not fully grown nor has the subplacenta yet formed as in a normal 16-day conceptus.

\section{PLATE 2}

Figs. 7 to 10 are sagittal sections through 16- and 18-day conceptuses from normal and ovariectomized females. $\times 4.9$.

Fig. 7. No. 18. A 16-day conceptus from a parous ovariectomized female. The section shows the two halves of the placenta linked by a single strand of cells. The decidua is almost all haemorrhagic and the embryo, apparently just dead, is differentiated but very small.

Fig. 8. No. 11. Termination of pregnancy at 16 days; a conceptus from another parous ovariectomized female, with massive haemorrhage and degeneration of the decidua. The placental blood sinuses are congested. Differentiation of the embryo and of the chorioallantoic placenta has continued up to the final breakdown of the decidua.

Fra. 9. No. 9. A 16-day normal conceptus. The allantois has not yet extended to the placenta but the development of the subplacenta can be seen in other sections.

Fig. 10. No. 46. An 18-day conceptus from an ovariectomized female receiving progesterone only from Day 14. The haemorrhagic space has persisted in the decidua but is separated from the enlarged placenta by healthy decidual tissue. The embryo is somewhat retarded compared with a corresponding normal one but is well formed.

\section{PLATE 3}

Placental tissue, above, and decidual tissue, below, from conceptuses of normal and ovariectomized guinea-pigs. $\times 32$.

Fig. 11. No. 34. Placenta, with outgrowths into the decidua, in a normal 14-day conceptus (Fig. 1).

FIG. 12. No. 6. The placental tissue is poorly developed in contact with haemorrhagic degenerating decidua in a conceptus from a 14-day ovariectomized female.

FIG. 13. No. 18. Half of the divided placenta and degenerating decidua in Pl. 2, Fig. 7, a conceptus from a 16-day ovariectomized female.

Fig. 14. No. 50. Normal placental and decidual tissue from the conceptus of a 16-day female, ovariectomized and given progesterone (Fig. 6). 
PLATE 1
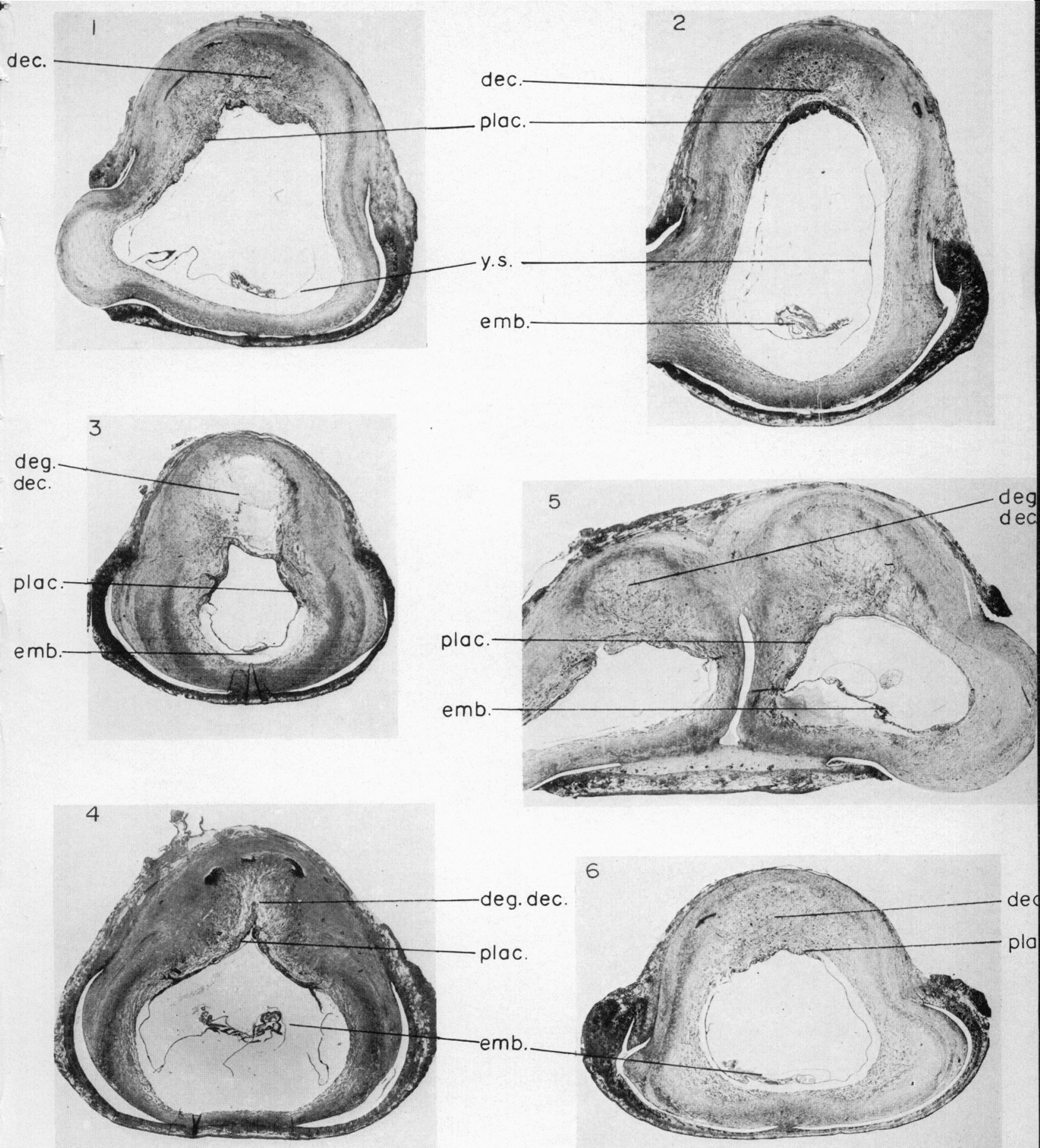

(Facing p. 244) 
PLATE 2

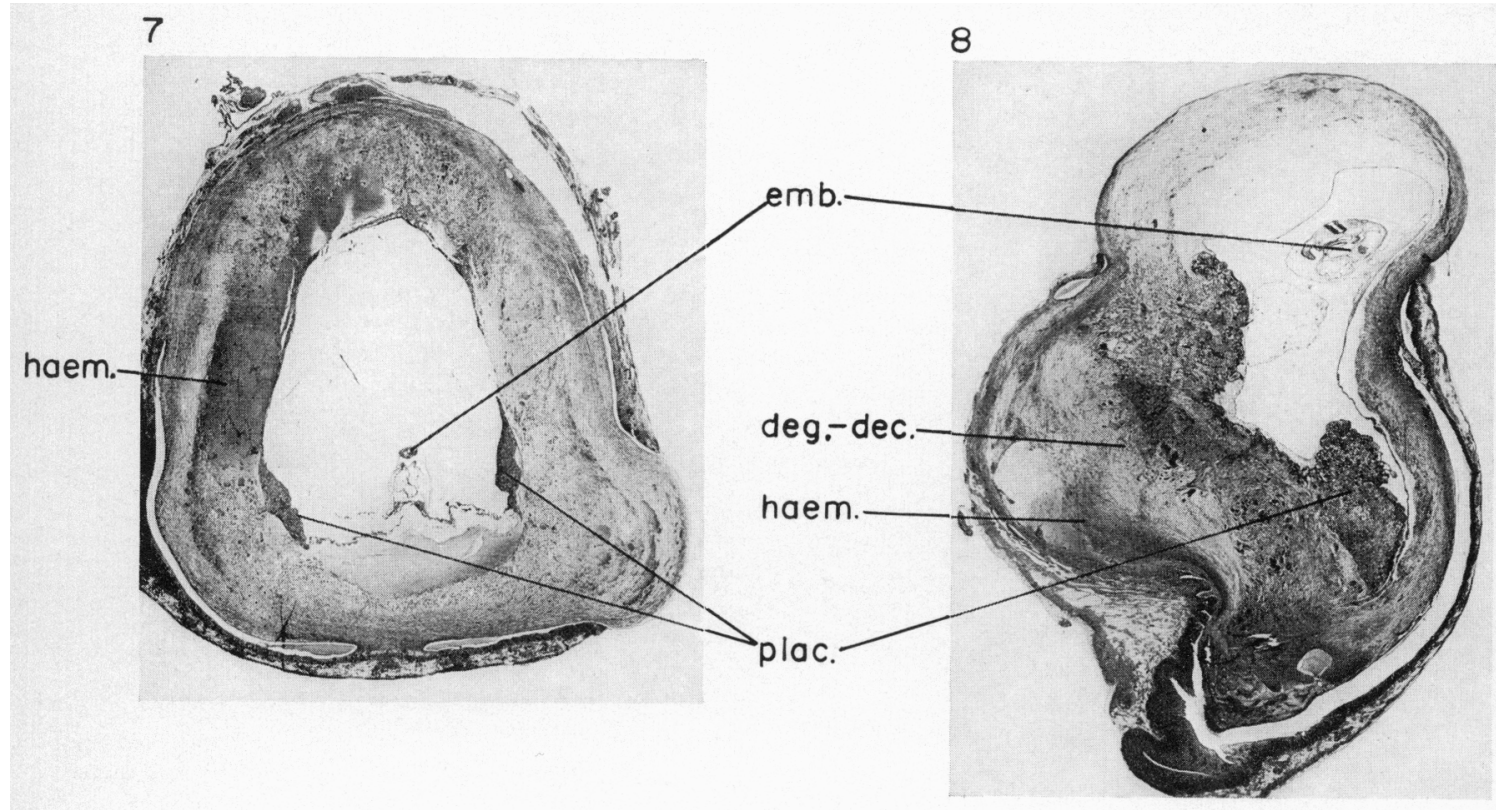

10

9

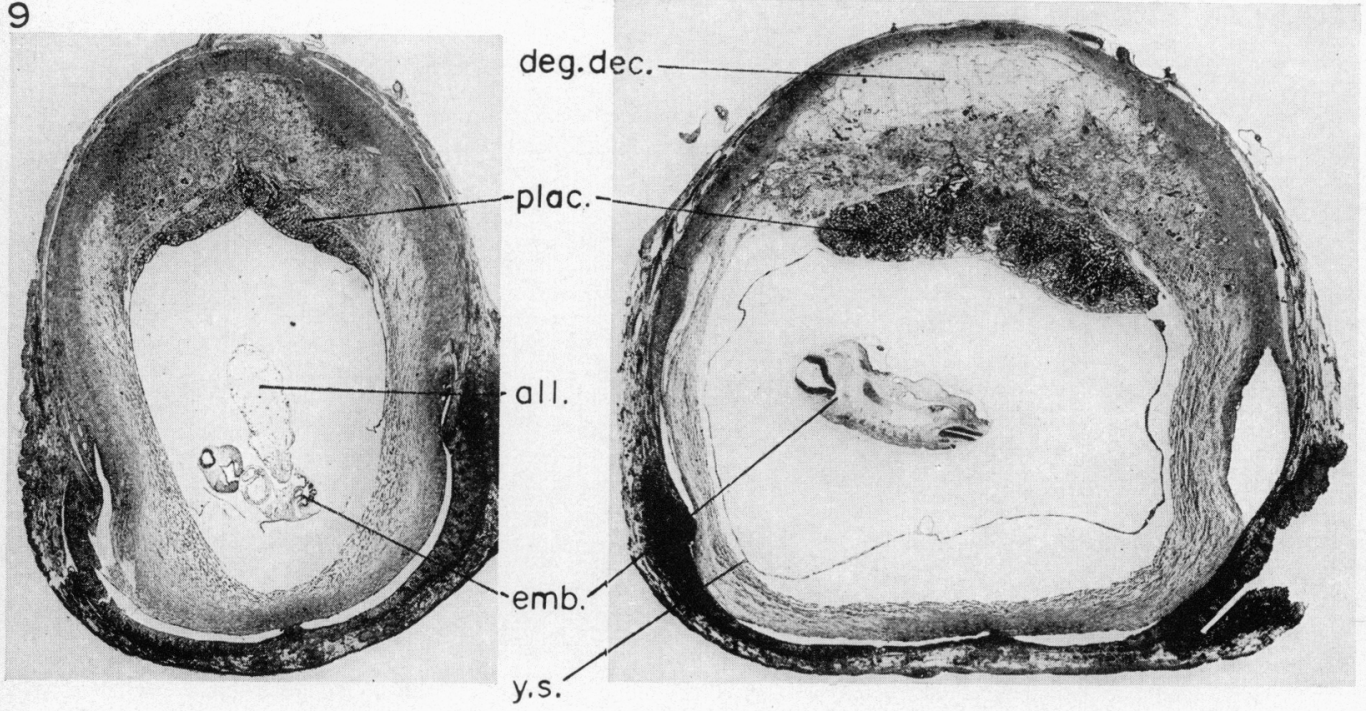



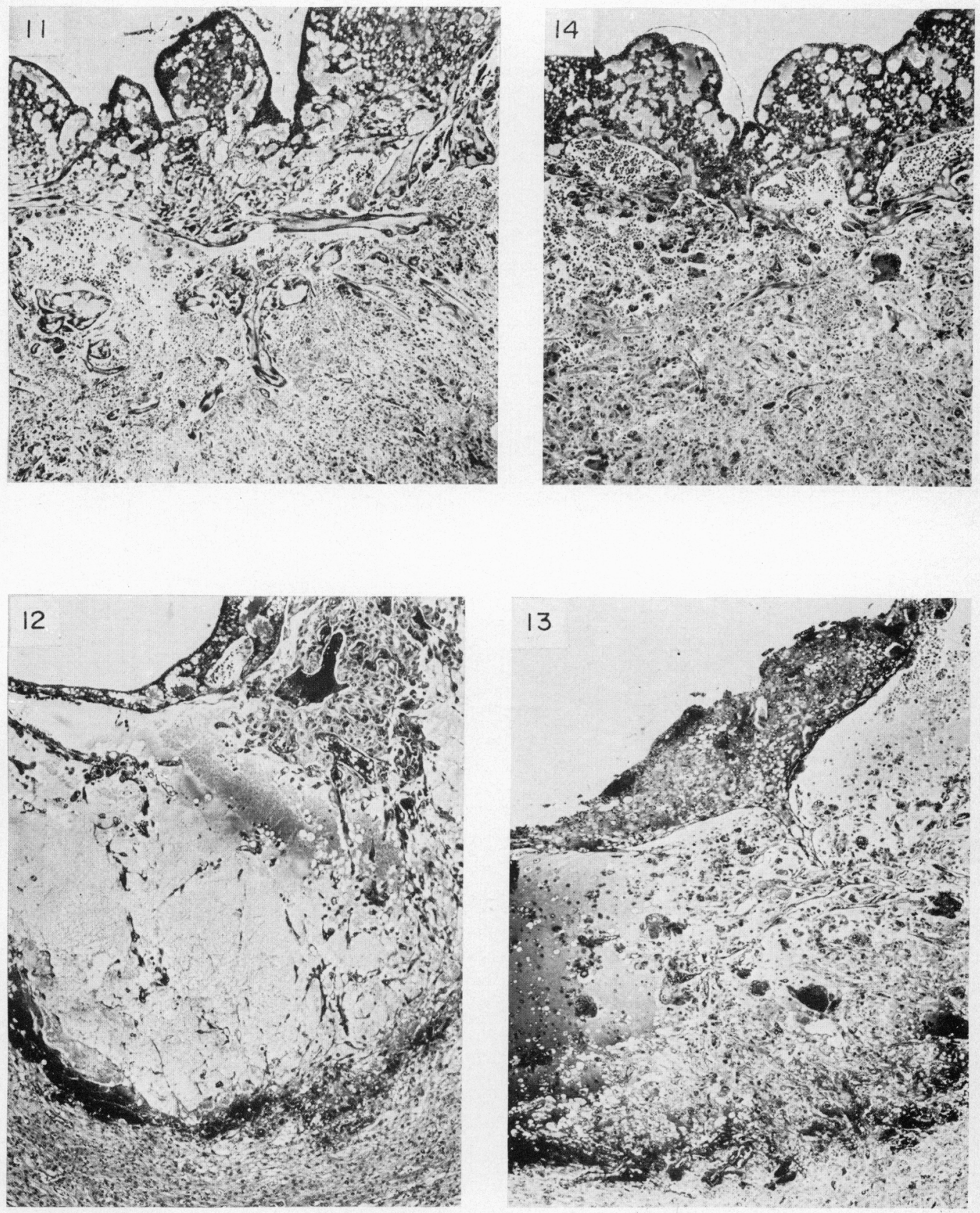
massive haemorrhage with an unevenly developed placenta and a retarded embryo, both of which still contained dividing cells. A later stage of the process is shown in Pl. 2, Fig. 7 and Pl. 3, Fig. 13 from a 16-day ovariectomized guinea-pig, where the conceptus contains a small dead embryo, the decidua is haemorrhagic and the placental tissue is displaced.

It is at 16 days that the contrast between the conceptuses of normal and ovariectomized females is most striking. In the former, embryos and placentae, including subplacentae, have grown and differentiated and in three out of six the allantoic vessels had vascularized the placenta; in the others, the allantois was large but still projecting freely into the exocoelomic cavity (Pl. 2, Fig. 9).

In all four ovariectomized females, the 16-day conceptuses were regressing; there was massive decidual degeneration and extravasated blood (Pl. 2, Fig. 7 and Pl. 3, Fig. 13), sometimes causing displacement of the embryo when the uterus was cut between implantation sites. Embryos were small in two females but, in another, a well grown embryo, placenta, subplacenta and chorioallantoic placenta could be seen (P1. 2, Fig. 8). Development appeared to have been fairly normal up to about 15 days, but shortly before death complete decidual breakdown with profuse haemorrhage had taken place terminating pregnancy. Gell divisions could be found in the placenta and were numerous in the subplacenta. The placental sinuses were very congested. In the fourth 16-day ovariectomized female, the conceptus was of normal shape, but no embryo was present, only a blood clot. Placental tissue, in contact with degenerated decidual tissue, was seen adjacent to the blood clot and to the uterine lumen as in Pl. 2, Fig. 7.

\section{Conceptuses in ovariectomized guinea-pigs receiving exogenous progestagens}

Sections were cut through conceptuses from three ovariectomized females killed on Day 16; two had received progesterone from Days 7 and 12, respectively, and the third had received norgestrel from ovariectomy on Day 4. In the first two, the conceptuses were small and retarded but developing normally, with no decidual degeneration (PI. 1, Fig. 6 and Pl. 3, Fig. 14). In the third female the conceptus was large and well developed but it showed characteristic mesometrial areas of degenerated decidua near the placenta, but not in contact with it. Apparently, owing to slow absorption, some decidual degeneration took place before it was checked by the progestagen. Placenta and embryo grew normally.

A similar area of decidual degeneration, with the remains of haemorrhage could be seen in sections through a conceptus from a female given progesterone from Day 14 and killed on Day 18. Plate 2, Figure 10 shows this mesometrial area, not now in contact with the placenta, which, together with the embryo, has differentiated normally. Another 18-day conceptus from a female, given progesterone from Day 10, had continued to grow but also still showed the remains of early decidual degeneration.

\section{DISCUSSION}

The post-implantation stages of early development have received much less 
experimental study than has ovo-implantation. In the present work some of the effects of ovariectomy of the mother on the early development of the guineapig have been examined. As in most species, early ovariectomy causes termination of pregnancy, but the effects on the guinea-pig conceptus are gradual and progressive, up to Day 16 of pregnancy.

Examination of serially sectioned conceptuses from ovariectomized females has shown that an important factor in the retardation and early death of normally implanted embryos is the degeneration of the decidua, distinguishable by Day 11 or 12, about 6 days after implantation, and preventable by exogenous progesterone. The degenerating, haemorrhagic area lies in contact with the developing placenta which fails to grow normally. Degeneration is at first confined to the looser, mesometrial part of the decidua which is presumably more sensitive to progesterone deficiency than the rest; placental growth is slowed down and distorted.

According to Yochim (1971), it is progesterone which controls the uptake and utilization of glucose, which is required for the initiation (and presumably the maintenance) of decidualization. Degeneration of the decidua may therefore imply a glucose deficiency. It may also affect the fluid supply of the fetus (Arthur, 1969). Typically the active decidual cells contain glycogen and lipid, implying a nutritive rôle for the decidua, its products passing into the blood spaces (Finn, 1971).

Kirby \& Cowell (1968) maintained, as the result of experiments on mice, that trophoblast was naturally invasive unless curtailed by intact decidual tissue. In these guinea-pigs, on the contrary, placental trophoblast in contact with the regressing decidua was poorly developed and failed to become exceptionally invasive. This could be attributed to absence of the normal vascular connexions with the decidua or to a direct effect of the progesterone deficiency on the trophoblast, which, however, continues to show cell divisions.

Although about half of them die on or before Day 14, the conceptuses in ovariectomized females can remain viable for at least another day (Deanesly, 1963). By about Day 16, however, haemorrhagic degeneration spreads from the mesometrial area to the whole decidua and pregnancy is terminated, even where embryo and placenta had continued differentiating normally up to then. Significantly, this sudden collapse leading to abortion corresponds approximately in time to that of the traumatic deciduoma in a cyclic guinea-pig, when the corpora lutea regress abruptly before the next ovulation.

Variations in the rate of decidual degeneration probably account for observed differences in embryo survival and growth. In parous ovariectomized guinea-pigs, conceptuses may show less retardation and decidual degeneration than in ovariectomized first pregnancies. This can be due to a stronger luteal stimulus from more corpora lutea or greater responsiveness of the endometrium before ovariectomy.

Progesterone, given early in an adequate dose, can prevent the decidual degeneration, or check its spread once it has begun, inhibiting further cell loss and haemorrhage. Nevertheless, conceptuses which remain deficient in progestagen up to Day 14 or earlier, may still include an outer vacuolated area on Day 16 or 18, and a smaller one on Day 21, after active growth and differentia- 
tion of embryo and placenta have been resumed, following progestagen administration. This is probably due to a local absence of decidual cell division.

Although it is the breakdown of the decidua which is conspicuous, there is no reason to believe that other elements in the conceptus are unaffected by progesterone deficiency. The rapid recovery of placenta and embryo when progesterone is given suggests that they are reacting directly to improved nutritive conditions.

\section{ACKNOWLEDGMENTS}

A grant from the Medical Research Council and the hospitality of the Agricultural Research Council are gratefully acknowledged.

The norgestrel was supplied by Wyeth Laboratories.

\section{REFERENCES}

Arthur, G. H. (1969) The foetal fluids of domestic animals. F. Reprod. Fert. Suppl. 9, 45.

DEANESLY, R. (1963) Early embryonic growth and progestagen function in ovariectomized guinea-pigs. 7. Reprod. Fert. 6, 143.

DEANESLY, R. (1967) Normal growth and persistence of corpora lutea of both ovaries in the unilaterally pregnant guinea-pig. F. Reprod. Fert. 14, 519.

Edgren, R. A., Jones, R. C., Clancy, D. P. \& NAGra, C. L. (1968) Biological effects of norgestrel alone and in combination with ethinyl oestradiol. F. Reprod. Fert. Suppl. 5, 13.

Fins, C. A. (1971) The biology of decidual cells. Advances in Reproductive Physiology, Vol. 5, p. 1. Ed. M. W. H. Bishop. Logos Press, London.

Harman, M. T. \& Prickett, M. (1932) The development of the external form of the guinea-pig (Cavia cobaya) between the ages of 11 days and 20 days of gestation. Am. 7. Anat. 49, 351.

KIRBY, D. R. S. \& Cowell, T. P. (1968) Trophoblast-host interactions. In: Fleischmajer: EpithelialMesenchymal Interactions, p. 64. Williams \& Wilkins, Baltimore.

ScotT, J. P. (1936) The embryology of the guinea-pig. I. A table of normal development. Am. F. Anat. $60,397$.

Үоснгм, J. М. (1971) Intra-uterine oxygen tension and metabolism of the endometrium during the pre-implantation period. In: Biology of the Blastocyst, p. 363. Ed. R. J. Blandau. University of Chicago Press. 